\title{
Assessing the quality of life of the individual: the SEIQoL with a healthy and a gastroenterology unit population
}

\author{
HANNAH M. MCGEE, ${ }^{1}$ CIARAN A. O'BOYLE, ANNE HICKEY, KEVIN O'MALLEY \\ AND C. R. B. JOYCE \\ From the Departments of Psychology and Clinical Pharmacology, Royal College of Surgeons in Ireland, \\ Dublin, Ireland and the University Psychiatric Policlinic, University of Bern, Switzerland
}

SYNOPSIS Current methods of measuring quality of life (QoL) impose an external value system on individuals, rather than allowing them to describe their lives in terms of those factors which they consider important. The Schedule for the Evaluation of Individual Quality of Life (SEIQoL) was developed to overcome such limitations. The QoL of 42 healthy attenders at an international immunization clinic was assessed using SEIQoL. Judgement reliability was high $(r=0.74)$ and individuals' judgement policies accounted for a large percentage of the variance in overall QoL $\left(R^{2}=0.75\right)$ demonstrating the construct validity of judgement analysis in this context.

In a second study of QoL of out-patients suffering from irritable bowel syndrome (IBS) $(N=20)$ or peptic ulcer disease (PUD) $(N=20)$ was assessed using SEIQoL. Judgement reliability was lower $(r=0.54)$ although statistically highly significant $(P<0.01)$, and the variance in overall QoL judgements explained was high $\left(R^{2}=0.74\right)$.

SEIQoL is an acceptable, reliable and valid technique for measuring individual QoL that takes greater account of individual perspectives than traditional measurement approaches.

\section{INTRODUCTION}

Assessment of patient quality of life (QoL) is becoming increasingly important in medicine and the behavioural sciences (Hollandsworth, 1988) but the underlying concepts are complex and multidimensional. This is reflected both in the variety of measurement techniques available and the lack of agreement on definitions. Conceptualizations of QoL vary from the broadly socio-economic (e.g. Liu, 1973), to that of Quality-Adjusted Life Years (QALYs) (Williams, 1985), where QoL is expressed in terms of a trade-off between health status and life expectancy.

Illness and its treatment can have a major impact on many aspects that are highly relevant to individual QoL, such as cognitive, emotional and sexual functioning, life satisfaction and the

\footnotetext{
' Address for correspondence: Dr H. M. McGee, Department of Psychology, Royal College of Surgeons in Ireland, 123 St Stephens Green, Dublin 2, Ireland.
}

ability to fulfil economic and other social roles (e.g. Carey, 1974; Laborde \& Powers, 1980; Jenkins et al. 1983). Many methods have been sought to describe such effects; by 1981 it was estimated that over 250 methods measuring various aspects of QoL had been developed (van Dam et al. 1981). The measures now available include such widely used scales as the Nottingham Health Profile (Hunt et al. 1985), the McMaster Health Index Questionnaire (Chambers et al. 1982) and the Sickness Impact Profile (Bergner et al. 1981).

However, although the scales themselves (as well as the methods of rating and analysing them) have of course been derived by assessing the QoL of individuals, the items and the responses to them do not represent the free choice of the individuals who are subsequently investigated: the results are usually presented as sample means and deviations, and the tests will often (if inevitably) have been standardized in samples from populations other than those 
currently being tested. Furthermore, specific goals or behaviours important to individual QoL, such as attendance at religious services, or duck-shooting, are not represented adequately by broad questions about physical mobility or mental health. Even if this were the case, apparently similar behaviours do not have the same significance for all individuals desiring to experience them. Neither do they necessarily retain the same salience for a given individual with the passage of time nor, more importantly in the present context, over the course of an illness. Thus, such techniques cannot provide an individual measure of QoL for a specific person at a particular point in time. There is undoubtedly a need for such measures. Joyce $(1987,1988)$ recommends that QoL be defined as what the individual says it is and several of the many current definitions of QoL implicitly pre-figure this position, for example:

[QoL is] '.. the capacity of the individual to realize his life plans' (Cohen, 1982); and

[QoL is] '... the difference, at a particular period in time, between the hopes and expectations of the individual and the individual's present experience' (Calman, 1984).

In assessing QoL, an individual should be given the opportunity to identify these factors that are important to him or her and to indicate the relative importance of each to overall QoL. Far from making this possible, many current methods even assume that QoL can be described adequately by a third party such as a spouse or doctor (e.g. Spitzer et al. 1981), despite ample evidence that the ratings of third parties agree poorly with those obtained directly from the individual in question (e.g. Pearlman \& Uhlmann, 1988; Slevin et al. 1988).

Judgement analysis (JA) is derived from social judgement theory (Hammond et al. 1975) and permits individual judgements to be modelled mathematically (Stewart, 1988). The technique has already been widely used in medical research (e.g. Fisch et al. 1981; Kirwan et al. 1983; Bech et al. 1986) but has not previously been applied to the study of QoL. JA allows quantification of the relative importance of a number of factors to a particular judgement or decision. It appears particularly useful in measuring individual $\mathrm{QoL}$ since: (i) estimates can be obtained using either factors representing the individual perceptions
Table 1. Glossary of terms relevant to judgement analysis

$\begin{array}{ll}\text { Cue } & \begin{array}{c}\text { An item of information or factor used as a } \\ \text { basis for judgement } \\ \text { A set of cue values presented for judgement; } \\ \text { may also be called a cue profile }\end{array} \\ \text { Judgement task } \begin{array}{l}\text { A set of cases presented to the judge for the } \\ \text { purpose of obtaining a sample of his/her } \\ \text { judgements }\end{array} \\ \text { Judgement policy } \\ \begin{array}{l}\text { A quantitative representation of the basis for } \\ \text { an individual's judgement, derived from } \\ \text { calculating the weight attributed to each cue } \\ \text { and the regressions of these on the criterion }\end{array}\end{array}$

(See Hammond et al. 1975 for further description and discussion.)

of each respondent or those derived from standardized measures; (ii) the relative importance of each factor to the individual can be quantified; and (iii) the technique can measure the internal reliability and validity of each individual's judgement policy.

The studies reported here, on QoL in a healthy group (Study 1) and in a patient group attending a gastrointestinal clinic (Study 2), represent the first attempt to apply JA to the measurement of individual $\mathrm{QoL}$.

\section{STUDY 1. HEALTHY SAMPLE Method}

Sample

Forty-two healthy individuals, consecutively attending the Immunization Clinic of the Royal College of Surgeons in Ireland for appropriate vaccination and/or inoculation prior to travelling abroad, participated. The mean age of the sample was 29 years (range 19-51), 20 were male and 22 female.

\section{Procedure}

The Schedule for the Evaluation of Individual Quality of Life (SEIQoL) was developed by adapting JA to the task of measuring QoL (see Table 1 for standard JA terms). The method and its presentation were standardized throughout the studies.

Determination of cues The first stage was the elicitation of the five areas of life (cues) (see Table 1) considered most important by each individual in assessing their overall QoL. The five cues were elicited by means of a semistructured interview and will be referred to 


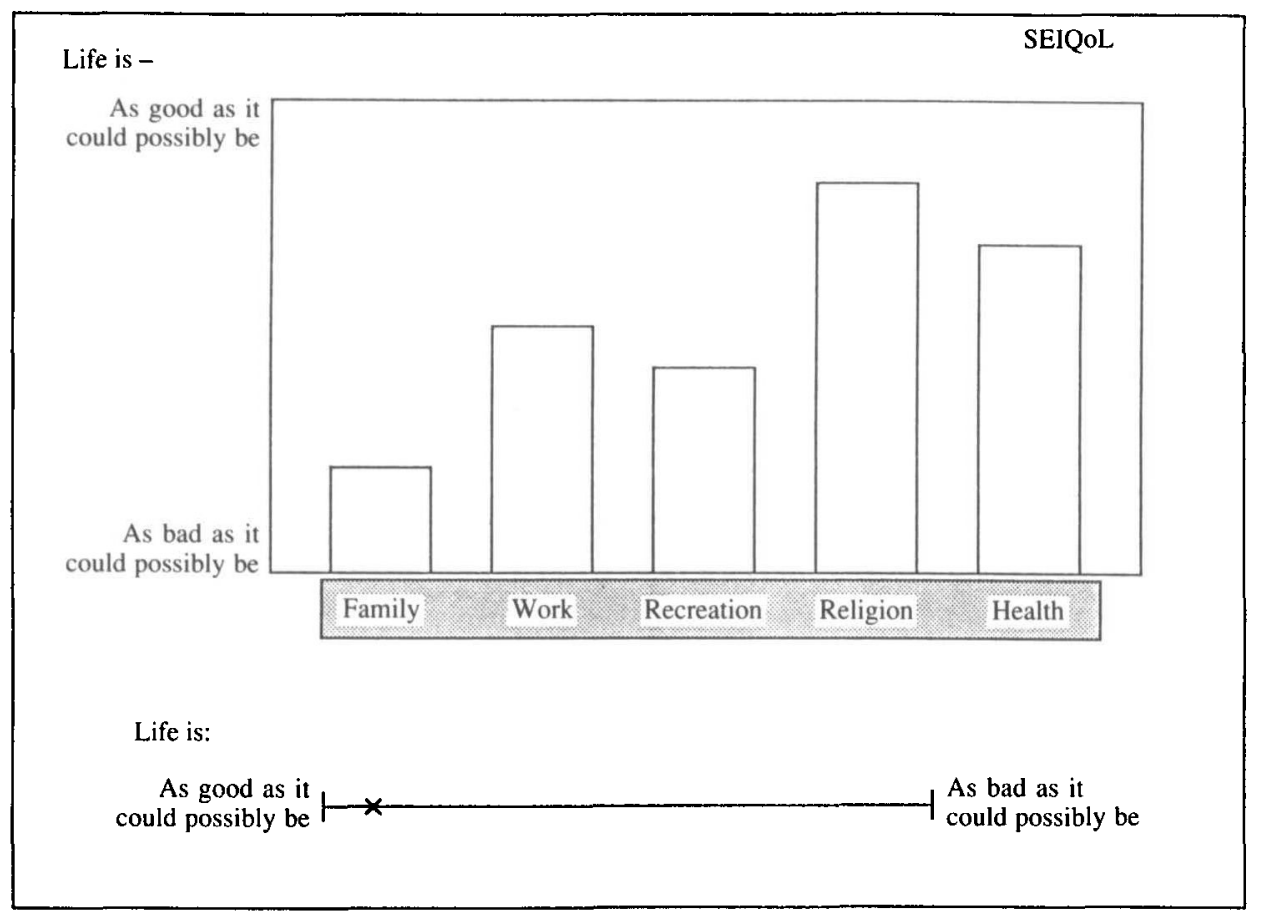

FIG. 1. Example of a cue profile depicting current level of functioning on one individual's five elicited QoL cues. (Shaded box represents the appropriate 'stick-on label', see text.)

henceforth as ELICITED CUES. The individual then rated his or her current status on each cue against a vertical visual analogue scale (VAS), labelled at the upper and lower extremes by the terms 'As good as could possibly be' and 'As bad as could possibly be', respectively (Fig. 1). These ratings were recorded by the interviewer as a bar chart, one bar representing each cue nominated by the individual (score range $0.0-$ 1.0). A horizontal VAS, similarly labelled, accompanied the bar chart and the individual made an overall rating of current overall QoL.

Elicitation of judgement policies The second stage quantified the relative contribution of each elicited cue to the overall judgement of QoL for that individual. Hypothetical cases (see Table 1) were presented for judgement. The cue profiles were in the form of bar charts which had been randomly generated in advance by computer, and were identical for all individuals with stickon labels bearing the name of each individual's five chosen cues. Each individual was required to estimate, on a horizontal VAS accompanying the profile, overall QoL given the particular hypothetical case. Thirty cases were presented for judgement. ${ }^{1}$ This task took an average of thirty minutes to complete.

Determination of judgement reliability In a JA task (see Table 1), reliability refers to the stability of judgements within a task. For example, if an individual judges overall QoL to be at a certain level given a particular combination of cues, then repeated presentation of the same combination should elicit the same overall QoL judgement. In order to determine judgement reliability, the set of cases presented therefore comprised 20 unique profiles and 10 randomly interspersed replicate profiles, as is standard in the JA procedure. The 10 pairs of judgements for each individual are then correlated to provide a reliability coefficient.

Derivation of scores Judgement policies (see Table 1) were extracted by analysing judgements

${ }^{1}$ See Policy PC (1986) for a discussion of appropriate case requirements. 
on the 30 hypothetical cases in the standard manner using Policy PC (1986), a programme based on multiple regression analysis. A global QoL score for the individual was then derived by multiplying each cue weight by the individual's current self-rating on that particular cue and summing these across the five cues. Consequently, the overall QoL score can range from 0 to 100 . Referred to as the ELICITED QoL, this score combines information about the individual's current status in salient life areas with the relative importance of those particular areas to him or her. Policy PC also directly estimates $R^{2}$ (the variance in QoL judgements explained by the set of cues used).

In order to compare the results obtained in this way with those obtained by imposing an external value system on the individual, as is done by traditional questionnaire methods, the SEIQoL procedure was repeated using cues provided from those frequently contained in standard QoL questionnaires: physical, emotional and social function, living conditions and general health. These are henceforth referred to as PROVIDED CUES, and the similarly estimated QoL as PROVIDED QoL.

\section{RESULTS}

A variety of areas of life were elicited from individuals as being important to their overall QoL (Table 2). A number of general themes emerged (often relating to those represented in standard instruments), for example, $16(38 \%)$ nominated work and $9(21 \%)$ mentioned aspects of living conditions as being important to their overall QoL. Surprisingly, not all individuals $(N=35)$ mentioned health.

These general themes were accompanied by many that were unique to a single individual, or mentioned by only a few. For instance, areas such as religion and education, which are not widely represented on the more traditional $\mathrm{QoL}$ instruments, were elicited. Among a miscellaneous section were areas such as politics and the environment.

Considerable variability was found in the relative importance attached by participants to the various aspects of their QoL. For example, the 35 people who nominated health as an important dimension attached weights to health varying from 3 to 59 out of a possible 100 . There
Table 2. Aspects of life (cues) nominated as most important to quality of life by healthy attenders at an immunization clinic and by out-patients attending a gastrointestinal clinic

\begin{tabular}{lccc}
\hline & & \multicolumn{2}{c}{$\begin{array}{c}\text { Gastrointestinal } \\
\text { clinic }\end{array}$} \\
& $\begin{array}{c}\text { Immunization } \\
\text { clinic } \\
\text { attenders } \\
\text { attenders }\end{array}$ & PUD & IBS \\
\cline { 3 - 4 } Aspect of life & $(N=42)$ & $(N=20)$ & $(N=20)$ \\
Relationships & $(\%)$ & $(\%)$ & $(\%)$ \\
Health & 86 & 50 & 55 \\
Family & 83 & 60 & 80 \\
Finances & 62 & 100 & 95 \\
Happiness & 60 & 35 & 60 \\
Work & 48 & 15 & 30 \\
Social \& leisure & 38 & 75 & 55 \\
Living conditions & 38 & 75 & 75 \\
Education & 21 & 30 & 30 \\
Independence & 19 & 15 & 5 \\
Religion & 19 & 10 & - \\
Miscellaneous & 7 & 30 & 10 \\
\hline \hline
\end{tabular}

PUD, peptic ulcer disease; IBS, irritable bowel syndrome.

Table 3. Range of weights calculated for five provided cues in judgement decisions on quality of life $(Q \circ L)$ by healthy individuals

\begin{tabular}{|c|c|c|c|c|c|}
\hline \multirow[b]{2}{*}{ Weight } & \multicolumn{5}{|c|}{ QoL cue } \\
\hline & $\begin{array}{l}\text { Physical } \\
\text { functioning }\end{array}$ & $\begin{array}{c}\text { Social } \\
\text { functioning }\end{array}$ & $\begin{array}{l}\text { Emotional } \\
\text { functioning }\end{array}$ & $\begin{array}{l}\text { Living } \\
\text { conditions }\end{array}$ & $\begin{array}{l}\text { General } \\
\text { health }\end{array}$ \\
\hline $\begin{array}{l}\text { Mean } \\
\text { Range }\end{array}$ & $\begin{array}{c}22 \\
(3-38)\end{array}$ & $\begin{array}{c}14 \\
(5-44)\end{array}$ & $\begin{array}{c}24 \\
(2-46)\end{array}$ & $\begin{array}{c}14 \\
(2-30)\end{array}$ & $\begin{array}{c}26 \\
(9-54)\end{array}$ \\
\hline
\end{tabular}

$N=42$.

was also wide variation in the weights given to the provided cues by different individuals (Table 3). The same global QoL score can be obtained in a number of different ways since cues, ratings and weights may differ from person to person. An example of this for two individuals is provided in Fig. 2.

The importance of individually generated weights for provided cues is illustrated in Fig. 3. Here, the two profiles are virtually identical and the overall QoL scores are very similar but the relevant cue weights indicate that emotional functioning and living conditions are of most concern for one individual while physical functioning and general health concerns are most important for the other. Mean QoL scores 


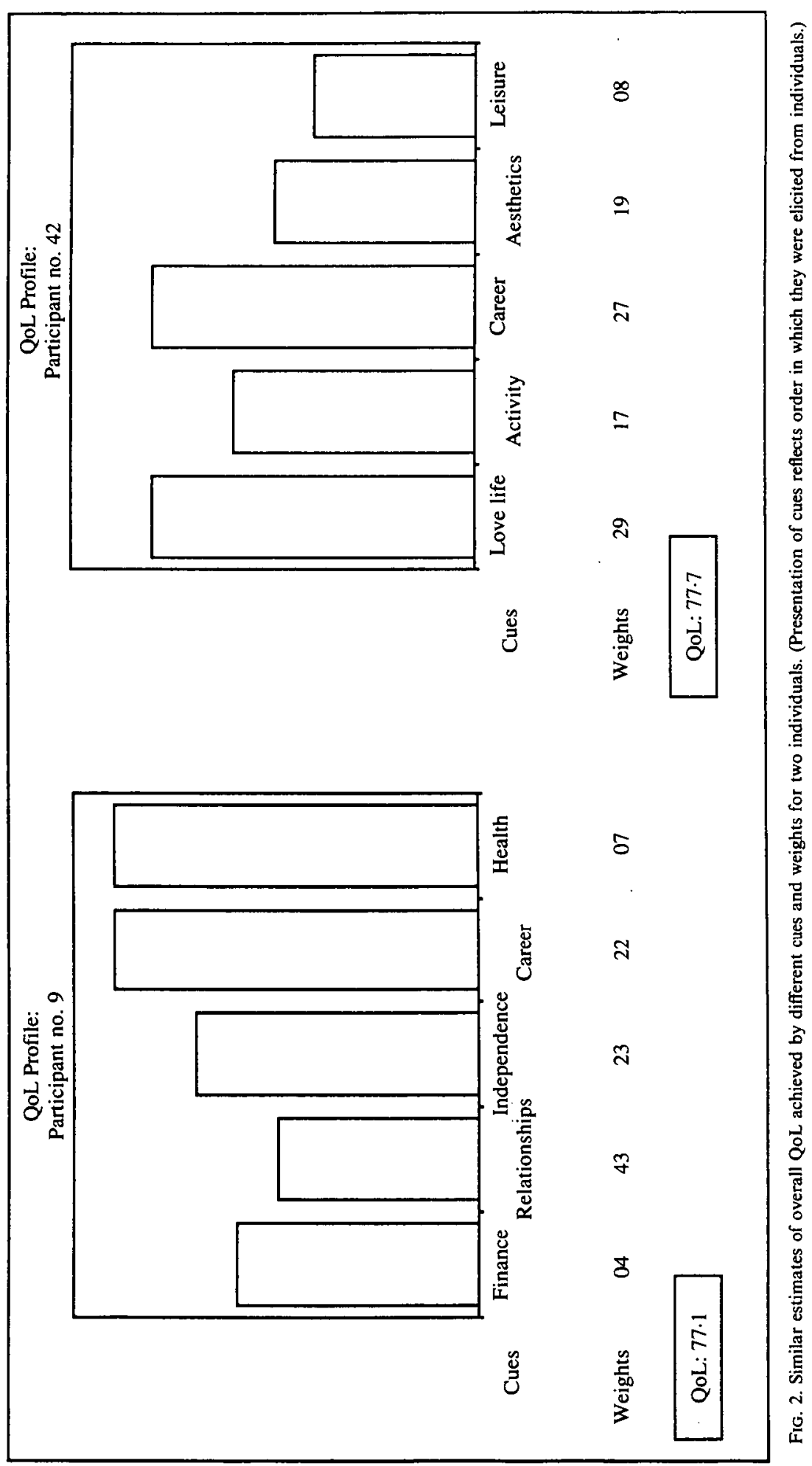




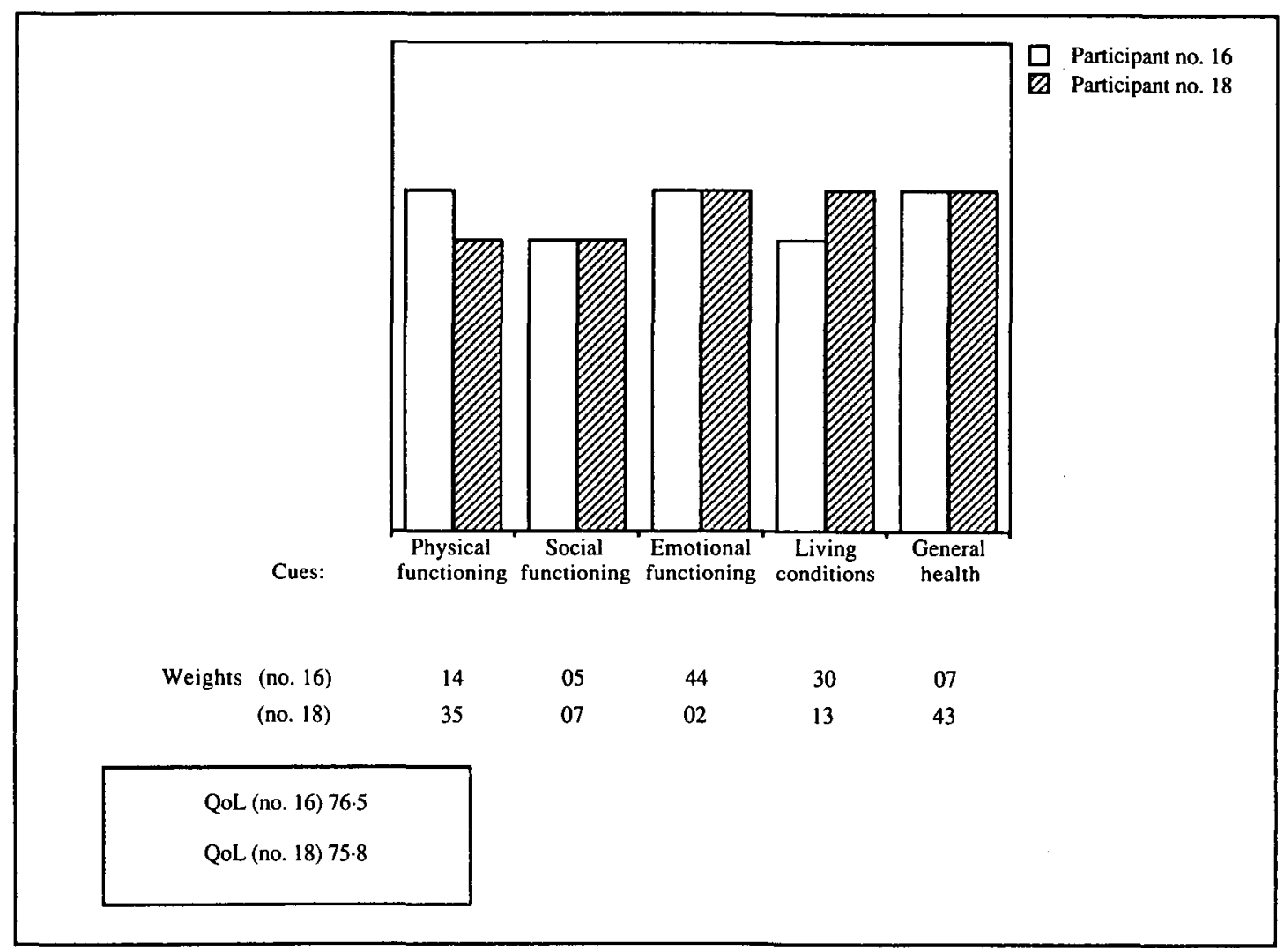

FIG. 3. Illustration of similar self-ratings of provided cues and overall QoL score yet different relative weights. (Arrangement of cues reflects order in which they were presented to individuals.)

derived from elicited and provided cues did not differ significantly (mean elicited QoL \pm S.D. $=$ $77.4 \pm 9 \cdot 5 ;$ mean provided QoL \pm s.D. $=$ $80 \cdot 0+7 \cdot 0$ ). A significant relationship was found between the two types of score (Pearson $r=$ $+0.49 ; t=3.57, P<0.001$ ) which, however, accounted for less than $25 \%$ of the common variability in the two sets of QoL scores.

Fig. 4 presents mean scores and frequency distributions of the reliability and internal validity scores. The level of agreement for repeated profiles was high indicating that judgements were being made consistently. The mean reliability (Pearson $r$ ) for replicate profiles was 0.74 for elicited and 0.69 for provided cues. Furthermore, derived judgement policies accounted for a high percentage of the variability in global QoL scores $\left(R^{2}=0.75\right.$ for elicited and 0.79 for provided cues).

\section{Discussion}

An implicit assumption in traditional QoL questionnaires is that the same cues (or questions) are appropriate for all individuals. Comparisons of elicited cues in this study between any pair of individuals suggest that this is not necessarily the case. From only 2 of 42 individuals was a virtually identical cue combination elicited (friends, health, family, job and finances/ money).

The overall QoL scores, derived from combining cue levels and weights, reflected the range of perceived QoL in this population. In order to obtain a clear picture of the status of a particular individual regarding a specific aspect of QoL, one must consider both the cue level and the cue weighting. An individual might have a low score on emotional functioning, for example, but the 


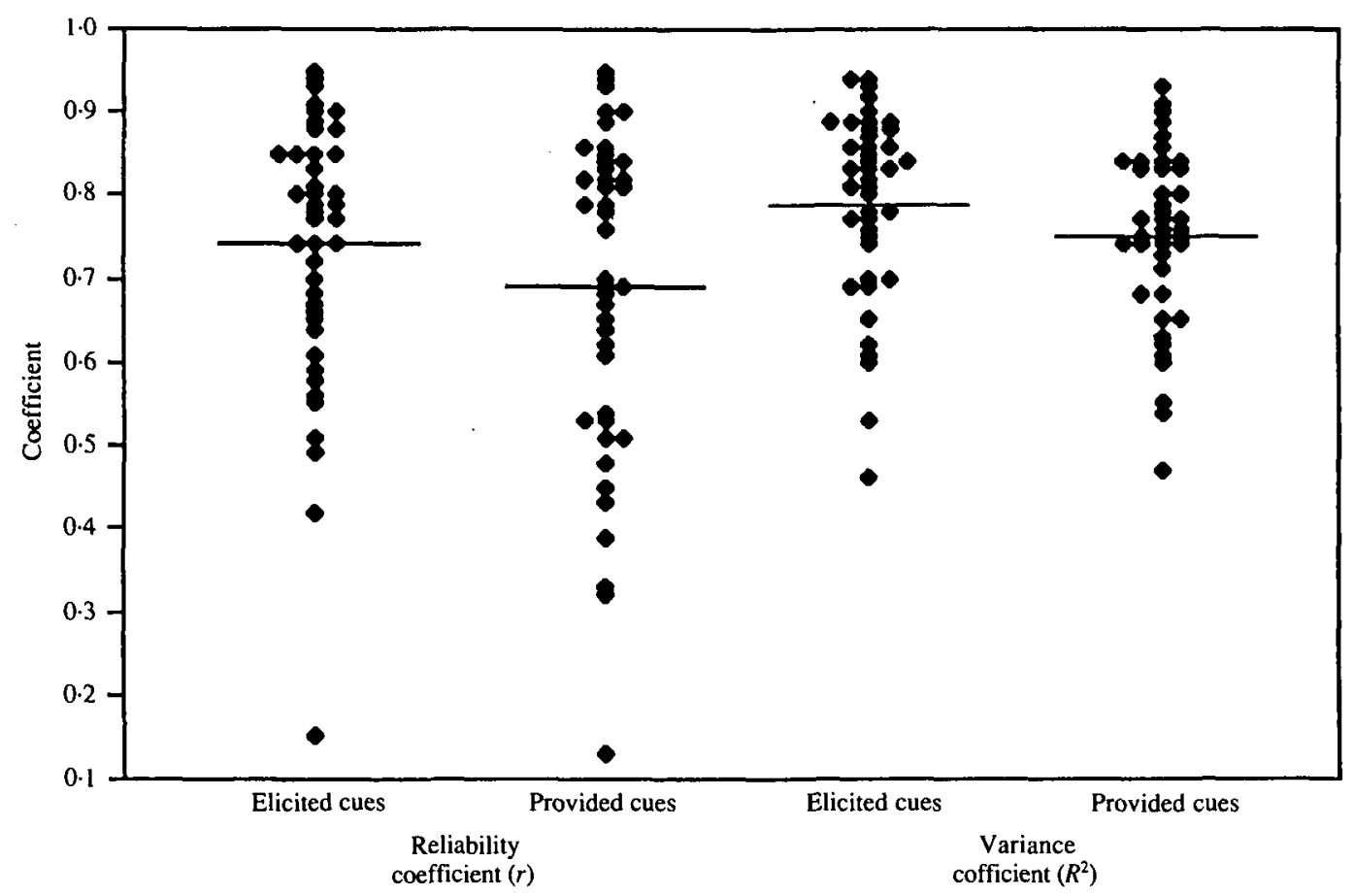

Fig. 4. Study 1 : internal consistency and explanatory power of judgement policies. Internal reliability coefficients refer to level of stability of judgements over 10 replicate cases. Variance coefficients refer to percentage of the global QoL score explained by the particular combination of cues.

significance of this is reduced if he or she attaches very little importance to this aspect of life. In the clinical context it is important to identify those particular areas of life of most concern to individual patients, so that proposed interventions can be considered in the light of their concerns.

With regard to the psychometric properties of the method, a small number of individuals exhibited low reliability on the replicate judgements (Fig. 4). There are many possible reasons for this finding including lack of comprehension of the task, fatigue or boredom, or a changing policy over the course of the task. Determination of the reasons for low reliability were beyond the scope of this first investigation but will be addressed elsewhere along with the implications of excluding invalid or widely divergent observations. The large amount of variance explained indicates that individuals provide and evaluate visually-presented information on various aspects of their lives and make valid QoL judgements about a range of life scenarios. The relationship between overall QoL scores, as determined by elicited cues and provided cues, appears to be a complex one. Although mean and standard deviation values are similar, correlation between the measures is relatively low. Thus, the estimate of individual QoL, derived by eliciting both cues and relative weights, is not equivalent to that from the semiindividualized format of eliciting relative cue weights for a series of provided cues.

\section{STUDY 2. PATIENT SAMPLE}

Common gastrointestinal disorders can affect a patient's sleep (Sjodin \& Svedlund, 1985), sexual functioning (Guthrie et al. 1987) and employment (Waller \& Miscewicz, 1969; Whitehead et al. 1982). These conditions tend to be chronic and relapsing (Holmes \& Salter, 1982; Tennant, 1988) and their deleterious impact on QoL is likely to be protracted. The impact on QoL of two of the most common gastrointestinal disorders, irritable bowel syndrome (IBS) and peptic ulcer disease (PUD), has not been widely studied. The purpose of the present study was to 
apply the SEIQoL to a patient population and to provide information regarding the impact of IBS and PUD on an individual measure of QoL.

\section{Method}

Sample

Forty-two consecutive attenders at a gastrointestinal clinic with either IBS or PUD were asked for consent to be interviewed on their medical condition and QoL. All but two PUD patients agreed to participate, resulting in a sample of 20 IBS and 20 PUD patients. The mean age of the sample was 35 years (range: 17-65) and there were 20 male and 20 female patients.

\section{Procedure}

Patients completed the SEIQoL in the standard manner described above for elicited QoL cues since the focus was one what patients themselves felt to be important for their QoL.

\section{Results}

All 40 patients fully understood and were able to complete the judgement tasks using SEIQoL. As in the case of the healthy sample, a wide variety of cues was elicited from the patient group (see Table 1). Leisure $\left(\chi^{2}=21.2 ; P<0.01\right)$, family $\left(\chi^{2}=18.9, P<0.01\right)$ and work $\left(\chi^{2}=4.8, P<\right.$ $0.05)$ were elicited significantly more often from patients, whereas they mentioned relationships $\left(\chi^{2}=16.9, P<0.01\right)$ happiness $\left(\chi^{2}=5.5, P<\right.$ $0.01)$ and independence $\left(\chi^{2}=8.4, P<0.01\right)$ significantly less often than did members of the healthy sample. There was no difference in the frequency with which financial affairs, living conditions, health, and educational and religious aspects of life were nominated. Rather fewer patients referred to health than did members of the healthy group (70 and $83 \%$ respectively).

Overall judgement reliability $(r)$ for the patient group, calculated using replicate judgement scores, was 0.59 . The QoL variance explained was $74 \%\left(R^{2}=0.74\right)$. The mean QoL of the IBS group (mean: 68.6 ; S.D.: 12.7 ) was significantly poorer than that of the healthy group (mean: 77.4 ; S.D.: $9.5 ; t=-3.02, P<0.01$ ) but not significantly different from that of the PUD group (mean $=74.0$; S.D.: $12.4 ; t=1.34 ; \mathrm{NS}$ ). No difference was found between the PUD and healthy groups (Fig. 5).

\section{Discussion}

It is noteworthy that health was mentioned somewhat less frequently by the patient group than the healthy group. It may be that the need for health is more likely to be seen by patients as self-evident, or as a means to an end, for instance as necessary for work and leisure, rather than as an end in itself. The overall QoL of IBS patients, as measured on the SEIQoL, was significantly poorer than that of the healthy sample, with QoL for the PUD patients falling between these two. This is in agreement with previous research and with the general clinical perception that IBS disrupts QoL to a greater degree than PUD (Latimer et al. 1981; Welch et al. 1985; Guthrie et al. 1987). Although these IBS patients were ambulatory, living in the community and continuing with activities of daily living such as employment, they were somewhat more likely to perceive that their QoL was impaired by their condition. The difference between PUD patients and the healthy sample was not significant, a finding also consistent with that of previous research (Nakagawa et al. 1979; Whitehead et al. 1982).

\section{GENERAL DISCUSSION}

This is the first attempt to measure individual patient QoL by judgement analysis. The basic method has been developed to permit application in a standardized manner, i.e. the SEIQoL. All participants were able to comprehend and complete the tasks required. The internal consistency (i.e. judgement reliability) of the technique was generally high in the healthy population although the range was wide. Consistency was somewhat less in the patient population and further research is required to determine the reasons for this. The internal validity of the technique was high in both the healthy and patient populations since a high percentage of the variance in global QoL was explained by the judgement policies in all circumstances. The SEIQoL has not been compared with standard instruments in the studies described here. The SEIQoL was devised because of the absence of a general measure of QoL that is nevertheless based on individual concerns. There is thus no 'gold standard' instrument against which the new measure can be evaluated. 


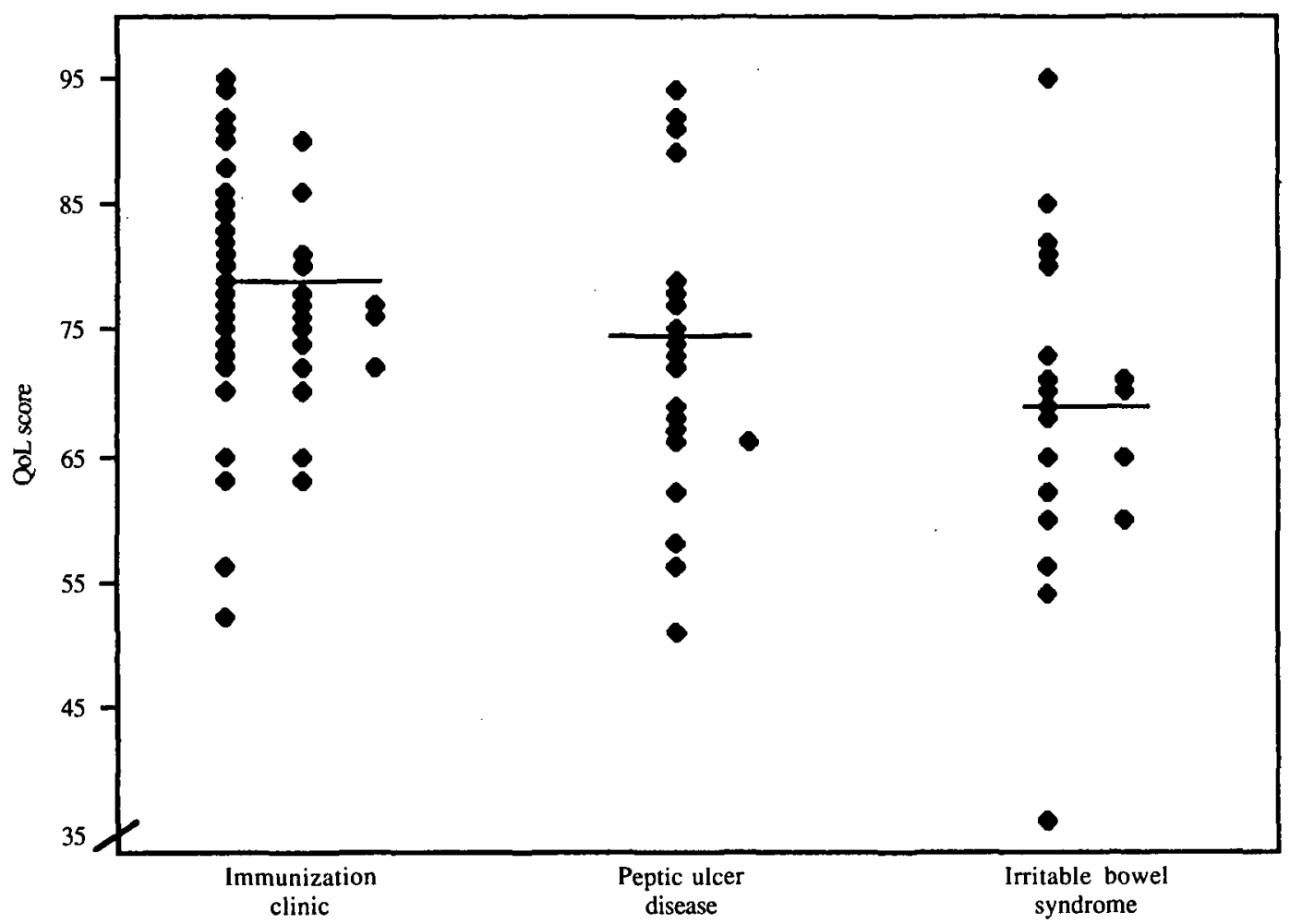

FIG. 5. Distribution of individual scores and mean values of QoL for three samples $(N=82)$.

Stability of the SEIQoL over time and the salience of original cues have not been addressed in these studies. A further study (O'Boyle et al. 1991) found excellent stability in a healthy population over a 32-week period.

The view that QoL is individual and phenomenological in nature (e.g. Cohen, 1982) is supported by the present work. A wide variety of cues which were considered important to QoL was elicited from participants in both studies. While a number of general themes emerged, many but not all participants nominating health for example, many themes, such as religion, were specific to individuals. Judgement analysis indicated that the relative importance of cues also differed from person to person. This was the case (in Study 1) for provided as well as elicited cues. In judging QoL the individual assesses the various aspects of his or her life in the context of their relative personal importance, which cannot be defined without reference to that individual. Therefore, the current practice of externally assigning the same weight to items, modules or total scores in questionnaires does not represent the real situation as perceived by any single individual. These findings also have implications for QoL measures that require an external observer such as a doctor or relative to rate a patient's QoL, for such an external rating may bear little relation to that of the patient. Patients' evaluations of their own lives are generally more positive than the evaluations made of them by external observers (Hamera \& Shontz, 1978; Pearlman \& Uhlmann, 1988; Slevin et al. 1988). This is also true of the general population. A study of major lottery winners revealed that they were no happier than community controls, with paraplegic patients reported as being less happy than both these groups but '... not nearly as unhappy as might be expected' (Brickman \& Coates, 1978).

Many so-called QoL techniques were in fact devised as health-status measures and focus exclusively on health. The present observations indicate that such an approach may be too narrow. Health was not mentioned by every 
patient, nor was it even the most frequently mentioned QoL aspect for patients; family, social and leisure activities were perceived as important by more patients than was health. Furthermore, health per se was actually mentioned less frequently by the patient group than the healthy group. The assumption that health is the only, or indeed the major, QoL priority for patients appears unjustifiable. Patients are as concerned, or more concerned in many instances, about aspects of their lives other than health. As Pearlman \& Uhlmann (1988) caution: [QoL is] ... a multidimensional construct that is more complex than a model based simply on health and functional ability'. Many health research workers concentrate exclusively on healthrelated QoL, an approach which the present findings indicate may be too narrow and even misleading given the complexity of the subject matter.

\section{CONCLUSIONS}

A new method of assessing QoL (the SEIQoL) was successfully administered to healthy individuals and patients. The results illustrated the wide variety of aspects considered important by different individuals in their evaluation of QoL. This raises many questions about current methods of measuring QoL, which are usually based on standard lists of aspects of life deemed important to QoL. Aspects considered important by an individual may not be included. Further assumptions of many current measures, that each aspect has a similar value for all individuals and is unvarying within individuals across time, may also be invalid. SEIQoL provides a means of obtaining individualized but nevertheless quantitative QoL information that may overcome some of the consequent limitations of current QoL methodology.

The new methodology is being studied in other medical conditions and therapeutic situations.

The authors are grateful for the assistance of Dr Nancy Gallagher and $\mathrm{Sr}$ Sheelagh Wickham of the Immunization Clinic, Royal College of Surgeons in Ireland, Dublin and Dr Ted Dinan and Mr Nap Keeling of the Gastroenterology Unit, St James's Hospital, Dublin. CIBA-GEIGY Ltd. (Switzerland) and the Royal College of Surgeons in Ireland kindly gave financial support.

\section{REFERENCES}

Bech, P., Haaber, A., Joyce, C. R. B. \& the Danish University Antidepressant Group. (1986). Experiments on clinical observation and judgement in the assessment of depression: profiled videotapes and judgement analysis. Psychological Medicine 16, 873-883.

Bergner, M., Bobbit, R. A., Carter, W. \& Gilson, B. (1981). The Sickness Impact Profile: development and final revision of a health status measure. Medical Care 19, 787-805.

Brickman, P. \& Coates, D. (1978). Lottery winners and accident victims: is happiness relative? Journal of Personality \& Social Psychology 36, 917-927.

Calman, K. C. (1984). Quality of life in cancer patients - an hypothesis. Journal of Medical Ethics 10, 124-127.

Carey, R. G. (1974). Emotional adjustment in terminal patients: a quantitative approach. Journal of Counselling Psychology 21, 443-439.

Chambers, L. W., McDonald, L. A., Tugwell, P., Buchanan, W. W. \& Kraag, G. (1982). The McMaster Health Index Questionnaire as a measure of quality of life for patients with rheumatoid disease. Journal of Rheumatology 9, 780-784.

Cohen, C. (1982). On the quality of life: some philosophical reflections. Circulation 66 (Suppl 3), 29-33.

Fisch, H. U., Hammond, K. R., Joyce, C. R. B. \& O'Reilly, M. (1981). An experimental study of the clinical judgement of general physicians in evaluating and prescribing for depression. British Journal of Psychiatry 138, 100-109.

Guthrie, E., Creed, F. H. \& Whorwell, P. J. (1987). Severe sexual dysfunction in women with the irritable bowel syndrome: comparison with inflammatory bowel disease and duodenal ulceration. British Medical Journal 295, 557-558.

Hamera, E. K. \& Shontz, F. C. (1978). Perceived positive and negative effects of life-threatening illness. Journal of Psychosomatic Research 22, 419-424.

Hammond, K. R., Stewart, T. R., Brehmer, B. \& Steinman, D. (1975). Social Judgement Theory. In Human Judgement and Decision Making (ed. M. Kaplan \& S. Schwartz), pp. 271-312. Academic Press: New York.

Hollandsworth, J.G. (1988). Evaluating the impact of medical treatment on the quality of life: a five year update. Social Science \& Medicine 26, 425-434.

Holmes, K. M. \& Salter, R. H. (1982). Irritable bowel syndrome -a safe diagnosis? British Medical Journal 285, 1533-1534.

Hunt, S. M., McEwen, J. \& McKenna, S. P. (1985). Measuring health status: a new tool for clinicians and epidemiologists. Journal of the Royal College of General Practitioners 35, 185-188.

Jenkins, C. D., Stanton, B. A., Savageau, J. A., Denlinger, P. \& Klein, M. D. (1983). Coronary artery bypass surgery: physical, psychological, social and economic outcomes six months later. Journal of the American Medical Association 250, 782-788.

Joyce, C. R. B. (1987). Psychosocial benefits. In Medicine and RiskBenefit Decisions (ed. S. W. Walker and W. Asscher), pp. 99-109. MTP Press: Lancaster.

Joyce, C. R. B. (1988). Quality of life: the state of the art in clinical assessment. In Quality of Life Assessment and Application (ed. S. W. Walker and R. M. Rosser), pp. 169-179. MTP Press: Lancaster.

Kirwan, J. R., Chaput de Saintonge, D. M., Joyce, C. R. B. \& Currey, H. F. L. (1983). Clinical judgement in rheumatoid arthritis II. Judging 'current disease activity' in clinical practice. Annals of the Rheumatic Diseases 42, 645-651.

Laborde, J. M. \& Powers, M. J. (1980). Satisfaction with life for patients undergoing hemodialysis and patients suffering from osteoarthritis. Nursing Health 3, 19-24.

Latimer, P., Sarna, S., Campbell, D., Latimer, M., Waterfall, W. \& Daniel, E. E. (1981). Colonic motor and myoelectrical activity: a comparative study of normal subjects, psychoneurotic patients and patients with irritable bowel syndrome (IBS). Gastroenterology 80 , 893-901. 
Liu, B. (1973). The Quality of Life in the United States, 1970. Midwest Research Institute: Kansas.

Nakagawa, T., Sugita, M. \& Ikemi, Y. (1979). Alexithymic features in digestive diseases. Psychotherapy and Psychosomatics 32, 191-203.

O'Boyle, C. A., McGee, H. M., Hickey, A., O'Malley, K. \& Joyce, C. R. B. (1991). But what does the patient think? Individualizing quality of life measurement in hip-replacement surgery. (Submitted for publication).

Pearlman, R. A. \& Uhlmann, R. F. (1988). Quality of life in chronic diseases: perceptions of elderly patients. Journal of Gerontology 43 , M25-30.

Policy PC (1986). Software for Judgement Analysis, Version 2.0 Reference Manual (1st edn.). Albany: Executive Division Services.

Sjodin, I. \& Svedlund, J. (1985). Psychological aspects of non-ulcer dyspepsia: a psychosomatic view focusing on a comparison between the irritable bowel syndrome and peptic ulcer disease. Scandinavian Journal of Gastroenterology 109 (Suppl), 51-58.

Slevin, M. L., Plant, H., Lunch, D., Drinkwater, J. \& Gregory, W. M. (1988). Who should measure quality of life, the doctor or the patient? British Journal of Cancer 57, 109-122.

Spitzer, W. O., Dobson, A. J., Hall, J., Chesterman, E., Levi, J., Sheperd, R., Battista, R. N. \& Catchlove, B. R. (1981). Measuring the quality of life of cancer patients. A concise QL-index for use by physicians. Journal of Chronic Diseases 34, 585-597

Stewart, T. R. (1988). Judgement analysis: procedures. In Human Judgment. The Social Judgment Theory View (ed. B. Brehmer and C. R. B. Joyce), pp. 41-74. North-Holland: Amsterdam.

Tennant, C. (1988). Psychosocial causes of deuodenal ulcer. Australian and New Zealand Journal of Psychiatry 22, 195-200.

van Dam, F. S. A. M., Somers, R., van Beek-Couzijn, A. L. (1981). Quality of life: some theoretical issues. Journal of Clinical Pharmacology 21, 166S-168S.

Waller, S. L. \& Miscewicz, J. J. (1969). Prognosis with the irritable bowel syndrome. Lancet i, 753-756.

Welch, G. W., Hillman, L. C. \& Pomare, E. W. (1985). Psychoneurotic symptomatology in the irritable bowel syndrome: a study of reporters and non-reporters. British Medical Journal 291, 1382-1384.

Whitehead, W. E., Winget, C., Fedoravicius, A. S., Wolley, S. \& Blackwell, B. (1982). Learned illness behaviour in patients with irritable bowel syndrome and peptic ulcer. Digestive Diseases \& Sciences 27, 202-208.

Williams, A. (1985). Economics of coronary artery bypass grafting. British Medical Journal 291, 326-329. 